\title{
Analysis of Critical Success Factors to Design E- waste Collection Policy in India: A Fuzzy DEMATEL Approach
}

\section{Shailender Singh}

Birla Institute of Technology and Science Pilani: Birla Institute of Technology and Science

\section{Mani Sankar Dasgupta}

Birla Institute of Technology and Science Pilani: Birla Institute of Technology and Science

Srikanta Routroy ( $\square$ srikanta@pilani.bits-pilani.ac.in )

Birla Institute of Technology and Science Pilani: Birla Institute of Technology and Science https://orcid.org/0000-0002-4592-0009

\section{Research Article}

Keywords: e-waste collection policy, technology involvement, green practices, environmental program, certification and licensing, circular economy, fuzzy DEMATEL

Posted Date: June 3rd, 2021

DOI: https://doi.org/10.21203/rs.3.rs-308039/v1

License: (c) (1) This work is licensed under a Creative Commons Attribution 4.0 International License. Read Full License

Version of Record: A version of this preprint was published at Environmental Science and Pollution Research on September 15th, 2021. See the published version at https://doi.org/10.1007/s11356-02116129-x. 


\title{
Analysis of Critical Success Factors to Design E-waste Collection Policy in India: A Fuzzy DEMATEL
} Approach

\author{
Shailender Singh ${ }^{\mathrm{a}}$, Mani Sankar Dasgupta ${ }^{\mathrm{b}}$, Srikanta Routroy $^{\mathrm{c}, *}$
}

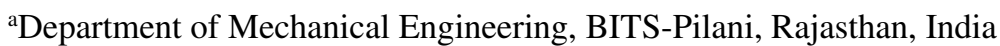
shailendersingh35@gmail.com

bepartment of Mechanical Engineering, BITS-Pilani, Rajasthan, India dasgupta@pilani.bits-pilani.ac.in

c,*Department of Mechanical Engineering, BITS-Pilani, Rajasthan, India srikanta@pilani.bits-pilani.ac.in

Abstract: The design of an e-waste collection policy is challenging, especially for a country like India, where the economy is developing state, and there is a large diversity in socio-economic factors. The e-waste collection policy has an impact on the various stakeholders such as the manufacturer, the raw material producers, the assemblers, the retailers, the generator (households and bulk consumers), the scrap dealers, the smelters and the recyclers as well as the regulators. The design of an e-waste collection policy needs to consider the appropriate set of Critical Success Factors (CSFs) which will maximize the e-waste collection providing business sustainability to the stakeholders at the same time satisfying the environmental regulations in the operating locations. Twenty-three CSFs identified along with six implication factors for e-waste collection policy framework based on a literature survey and experts view. The fuzzy DEMATEL approach is employed to analyze the CSFs to design an e-waste collection policy in India from a wide perspective. Cause and effect interrelationship is established among the CSFs, and also their impacts are evaluated to segregate the CSFs into cause group (prominent influencing and independent) and effect group (influenced and dependent). The CSFs such as technology involvement, green practices, environmental program, certification and licensing, public ethics and stakeholder's awareness for circular economy are prominent influencing CSFs for e-waste collection policy in India. The current study is expected to provide a platform for policymakers to design the e-waste collection policy.

Keywords: e-waste collection policy, technology involvement, green practices, environmental program, certification and licensing, circular economy, fuzzy DEMATEL

\begin{tabular}{llll}
\hline \multicolumn{2}{l}{ Taxonomies } & \\
\hline$\widetilde{\mathrm{A}}$ & Fuzzy direct relationship matrix & $\tilde{a}_{i j k}=\left(l_{i j k}, m_{i j k}, u_{i j k}\right)$ & $\begin{array}{l}\text { Degree of influence factor } i \text { on } \\
\text { factor } j\end{array}$ \\
$k$ & Number of experts & $\left(x l_{i j}, x m_{i j}, x u_{i j}\right)$ & Normalized value of $\left(l_{i j}, m_{i j}, u_{i j}\right)$ \\
$\min l_{i j}^{k}$ & Column minimum value of $l_{i j}$ & $\max u_{i j}^{k}$ & Column maximum value of $u_{i j}$
\end{tabular}




$\begin{array}{llll}x \mathrm{ls}_{i j}^{k} & \begin{array}{l}\text { Left spread measure of normalized } \\ \text { fuzzy number }\end{array} & x \mathrm{us}_{i j}^{k} & \begin{array}{l}\text { Right spread measure of } \\ \text { normalized fuzzy number }\end{array} \\ x_{i j}^{k} & \text { Total normalized crisp value } & z_{i j}^{k} & \text { Crisp value defuzzified from TFN }\end{array}$

27

\section{Introduction}

Handling policies of Electronic Waste (e-waste) or Waste of Electrical and Electronics Equipment (WEEE) are an essential aspect of environmental ethics of a country. The Electrical and Electronic Equipment's (EEEs) are generally categorized based on their usage and useful life for drafting the e-waste policy. While, EEEs play a vital role in modern life in terms of safety, comfort, education and entertainment, WEEE poses a severe environmental risk if not treated and disposed of appropriately. Due to rapid technological advancement, higher affordability, increasing purchase power, decreasing cost, shorter useful life cycle, increased customization and promotional events like exchange schemes, there is tremendous increase in consumption of EEEs all over the world. For example, the present penetration rate of mobile subscribers worldwide is $67 \%$ and expected to reach $71 \%$ in 2025 (GSMA 2019). The expected life cycle of EEEs like mobile phones at present is shorter than two years while computers have a useful life of about three years (Öztürk 2015). This ever-shortening life span of EEEs contributes to a great extent to WEEE growth. According to the various sources (Ayodeji 2011; Baldé et al. 2017), the worldwide increase in e-waste generation at present is assessed to be at a rate of $10 \%-20 \%$ annually. There is great concern about lack of government support and ineffective regulatory framework on e-waste handling in many countries, resulting in a continuous increase in informal recycling activities that pose a serious risk to the environment as they can bypass environmental regulations (Al-Anzi et al. 2017). Unscientific e-waste handling is causing severe damage to the environment by contaminating soil, water and atmosphere, ultimately affecting human lives (Cao et al. 2016). Hence, appropriate policy implication in e-waste handling is of critical importance for a country and its well-being, and it necessitates social awareness drive to tackle the problem.

A recent study by Forti et al. (2020) revealed that only 78 countries in the world have national legislation on e-waste handling. There is great diversity across the world, majority of the developed countries such as Europe, America and Oceania have implemented robust e-waste policy and established necessary infrastructure for collection and processing of e-waste (Wath et al. 2010). They also successfully managed their social awareness programs and education in the past. For instance, more than $50 \%$ of Switzerland's citizens expressed a desire to place the highest emphasis on environmental issues as recorded in a survey (Chaudhary and Vrat 2018). Most of the developed nations also have introduced provision for steep penalty for improper handling of e-waste (Wath et al. 2010). 
In contrast, in developing countries such as India, the regulatory framework and vigilance are inadequate for mitigating WEEE related issues at the same time general public awareness is also deficient. As a result, a large part of e-waste gets dumped or transported from developed countries as a donation, or hands-down etc. (Garlapati 2016). Some of the direct causes identified by (Thavalingam and Karunasena 2016) in developing nations are insufficient corrective measures, unclear roles of stakeholders and insufficient investment of resource in the e-waste management sector. These are challenges believed to be arising out of lack of social awareness and inadequate legal $\&$ enforcement framework. The same gives rise to informal or grey sector handling a vast amount of e-waste as observed and recorded for Bangladesh, Malaysia, Indonesia, Philippines and Brazil (Rodrigues et al. 2020). The situation is not much different in case of India.

Apart from technological shortcomings, one of the problems for India is its very large population. India is at present ranked third in the world in terms of e-waste generation, which is assessed as 3.23 million tons (Forti et al. 2020). The estimated volume of e-waste generation in India grossly exceeds that of e-waste processing capacity ( 0.78 million tons) in the country as observed by CPCB (2019). As per the assessment carried out in 2017 (Awasthi et al. 2018), the various sources that prominently contribute to the growth of e-waste are household appliances (42\%), information and telecom equipment (34\%), consumer electronics (14\%) and other electronic equipment (10\%). Many regulatory agencies also pointed out laxity in the implementation of e-waste policies as well as lack of enforcement as a prominent drawback in India (Jecton and Timothy 2013).

For successful implication of e-waste collection policy, it is of paramount importance to monitor its outcomes from time to time and identify the need for government involvement in policy amendments (Wang et al. 2017). Further, the stakeholders need to play a responsible role in the implementation of e-waste collection policy and also to spread environmental awareness among people. Okorhi et al. (2017) presented a survey of various effects of implementation of e-waste collection policy, including the involvement of local government as well as solid waste handling agencies. They suggested that e-waste management is distinctly different from municipal solid waste management and emphasized the need of setting up independent standards for e-waste regulation by the government. Wath et al. (2011) argued that the framework for e-waste collection policy should maintain a balance between the economics involve and environmental and public health \& safety concerns. Morris and Metternicht (2016) stated that for enhancement in the effectiveness of e-waste collection policy, it is important to re-assess the roles and responsibilities of stakeholders. Furthermore, identical enablers are required for cases having the involvement of the local as well as the federal government to engage and educate the public on the need of separate e-waste management and the various priorities of the e-waste collection policy. 
The present work attempts to identify the Critical Success Factors (CSFs) influencing the designing of e-waste collection policy in the Indian context. The motivation of this research work is to develop an interrelationship among the various influencing factors and thereby assist the policymakers in incorporating these factors to strengthen the e-waste policy in terms of collection. Besides, policymakers need to set appropriate standards and controls to regulate the action of stakeholders associated with e-waste handling in the public and private sector. To meet the objectives of our study Multi-Criteria Decision Making (MCDM) technique through an appropriate framework is adopted. Fuzzy Decision Making Trial and Evaluation Laboratory (DEMATEL) is chosen for evaluating the CSFs. As it has the capability to analyse the influencing behaviour of CSFs on other CSFs. The method is utilized, primarily to develop two sets of CSFs that is cause group and effect group considering multiple expert judgments and the fuzziness associated with their judgments.

\section{Evolution of e-waste policy in India}

With a motive to mitigate short and long term impact on environmental and human health arising out of e-waste, the Indian government has enacted several e-waste policies from time to time. The evolution of the e-waste policy in India may be classified into five phases (CPCB 2019), as illustrated in Fig. 1.

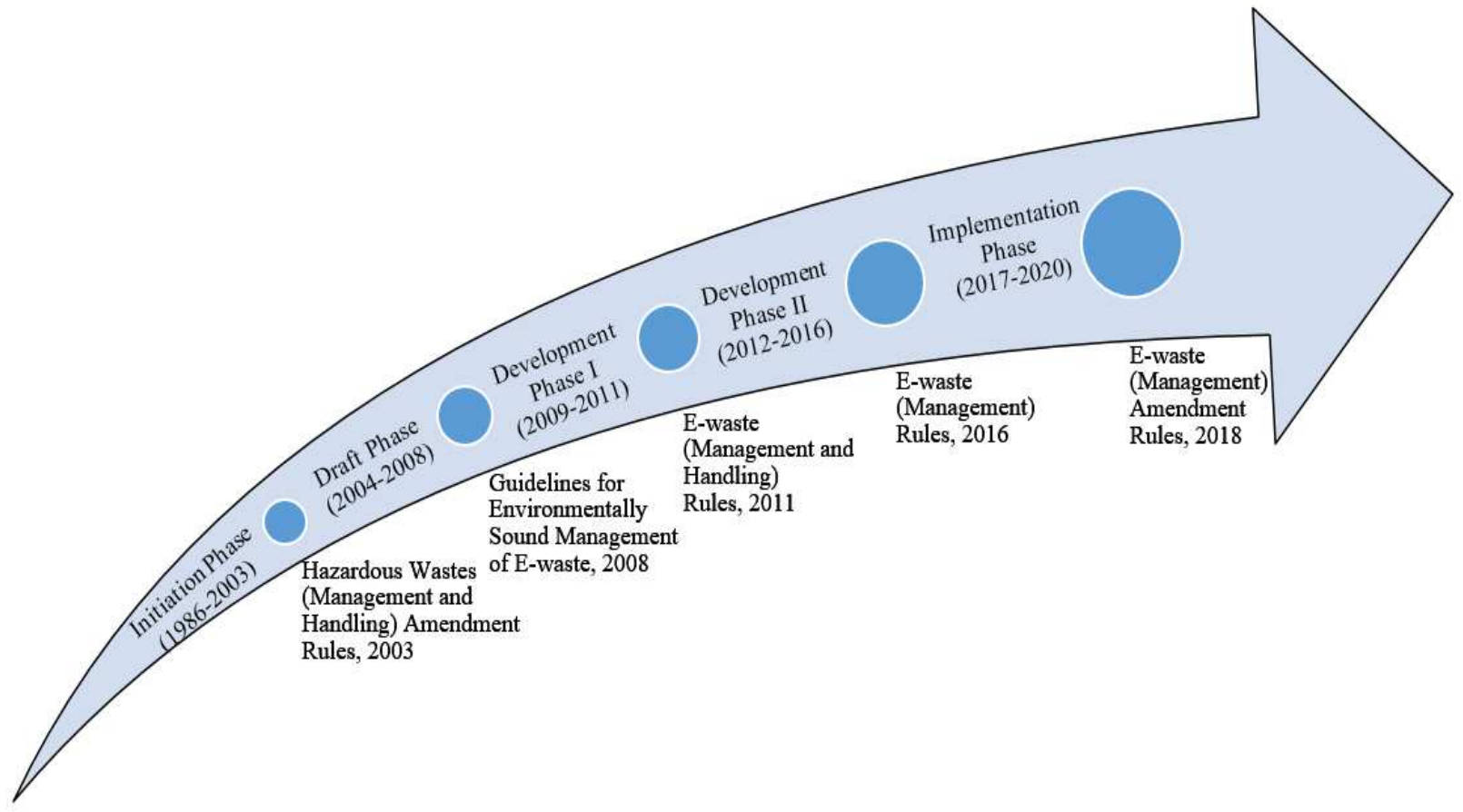

Fig.1. Evolution of e-waste policy of India

100 The period during 1986 to 2003 can be termed as initiation phase as several pioneering initiatives were taken during this phase to identify, categorize and assign the responsibility of handling various waste streams. Acts such as 
Environment protection Act 1986 was brought in, to identify various types of pollutants to the environment. After about three years, Hazardous (Management and Handling) Rules 1989 was introduce to define hazardous wastes and their sources. Subsequently, a series of Hazardous (Management and Handling) Amendments in 2000 and 2003 were brought forward which identifies and categorizes various harmful wastes into twelve categories. The term ewaste was introduced and recognized as a waste stream with contamination potential under schedule three of the hazardous waste rules in 2003. There was no separate regulation explicitly formulated to address the e-waste related problem. However, this can still be considered as a profound first step taken to subsequently develop specific legislation for various waste streams and environmental issues arising out of it.

During 2004 to 2008, several studies were commissioned, and detailed guidelines were drawn, this time interval can be defined as the Draft phase. An explicit formulation of guidelines for environmentally sound management of ewaste was initiated by the Ministry of Environment and Forest (MoEF) and Central Pollution Control Board (CPCB), Government of India in the year 2008. Under this initiation, identification and assessment of various sources of e-waste were made. Classification of e-waste according to its components, composition, and harmful effects were attempted. These documents also addressed the recycling potential of e-waste for economic benefit. However, the guidelines of e-waste did not adequately explain the roles and responsibilities of various monitoring agencies such as State Pollution Control Boards (SPCBs), local bodies, as well as other stakeholders.

The period during 2009 to 2011 can be termed as a Development Phase-I as the first consolidate policy framework on e-waste management was debated during 2010-11 and was passed in 2011 which was termed as E-waste (Management and Handling) Rules, 2011. The policy laid down the roles and responsibilities of stakeholders and monitoring agencies. It also introduced the concept of Extended Producer Responsibilities (EPR) in India although was in place in developed nation. This policy defined various stakeholders of a business model around e-waste management, grouped under manufacturer, producers, collectors, dismantlers, and recyclers. The Development Phase-I, however, fell short of defining transboundary movement of e-waste under various schemes as a hazardous and a mitigation plan for the same. Other criticisms are that it did not adequately address economic implications, merits, demerits, barriers and drivers of e-waste management in India (Wath et al. 2010).

The next distinct phase identified is from 2012 to 2016 as Development Phase-II. The levels of responsibilities of the various government bodies were explained in the E-waste (Management) Rules, 2016, and it is presented in Table 1. The prominent feature of this policy was a target-based approach for e-waste collection under EPR. The adoption of the same policy was based on existing international best practices which demonstrated a higher success rate for implementation of EPR. The policymakers took references from many countries like the Netherlands 
(recycling rate 45\%-75\%), Japan (recycling rate 50\%-60\%), South Korea (recycling rate 55\%-70\%) and UK (recycling rate 50\%-80\%) (CPCB 2019). In these countries, the e-waste management policy was in a much more mature phase with set targets of recycling rate. Whereas in India, successful and sustainable collection infrastructure was not yet established. Further, the implementation plan of this rule for the producer under EPR provision was to subsequently set a guideline of collection target. During the first two years, the recommended target was $30 \%$, and the subsequent bi-yearly target was increased by $40 \%$, and so on up to $70 \%$ (CPCB 2019). Under the rule, the producers were required to share the details of EEEs and collection target of the forthcoming years based on sales forecast to the CPCB in a prescribed format.

The development during the year from 2017 to 2020 can be term as implementation year. The policymakers duly considered the feedback obtained from various stakeholders to formulate a comprehensive E-waste (Management) Amendment Rules, 2018. The provision in this rule was that producers should be liable to share collection targets with government authorities. Another condition was that in the event of any violation of environmental law, strict action might be taken in the form of cancellation of registration.

Table 1: Responsibility of government authorities in e-waste legislation, India

\begin{tabular}{|c|c|c|}
\hline Level of authority & Entities & Responsibilities \\
\hline Central government & $\begin{array}{l}\text { MoEF, CPCB, general } \\
\text { administration }\end{array}$ & $\begin{array}{l}\text { Draft policy \& regulations, Training program, } \\
\text { Random inspections, Submission of the annual } \\
\text { report }\end{array}$ \\
\hline State government & $\begin{array}{l}\text { SPCB, committees of union } \\
\text { territories, general } \\
\text { administration }\end{array}$ & $\begin{array}{l}\text { Inventorization of e-waste, Grant \& authorization, } \\
\text { Maintaining online information, Monitoring, } \\
\text { Random inspection }\end{array}$ \\
\hline Urban local bodies & $\begin{array}{l}\text { Municipal } \\
\text { committee/council or } \\
\text { corporation }\end{array}$ & $\begin{array}{l}\text { Ensure E-waste to be separate with municipal } \\
\text { solid waste, collection of orphan e-products and } \\
\text { sent to authorized recyclers }\end{array}$ \\
\hline Port/Customs Authority & $\begin{array}{l}\text { Dock committee for } \\
\text { transboundary movement }\end{array}$ & $\begin{array}{l}\text { Verify the importer authorization, Monitoring } \\
\text { illegal activities, Reporting to CPCB }\end{array}$ \\
\hline
\end{tabular}

As of $27^{\text {th }}$ July 2019, CPCB had registered a total of 312 authorized recycling/dismantling units across India (CPCB 2019). The units are located in 18 states, as shown in Fig. 2, and the overall registered recycling capacity was 0.78 million tons. The highest number of recycling units are located in the state of Maharashtra (75 units) followed by 71 units in Karnataka and 41 units in Uttar Pradesh. Out of the total formal recyclers, only 51 units had installed capacity exceeding 5000 tons per annum. The total installed capacity of registered recyclers was 0.78 million tons which were four times lesser than the projected e-waste generation of 3.23 million tons. Several studies have revealed that the implemented e-waste policy in India, along with other developing countries face unique challenges (Patil and Ramakrishna 2020; Singh et al. 2020). These include thriving informal sector in the absence of strict 

intervention steps needed to manage e-waste.

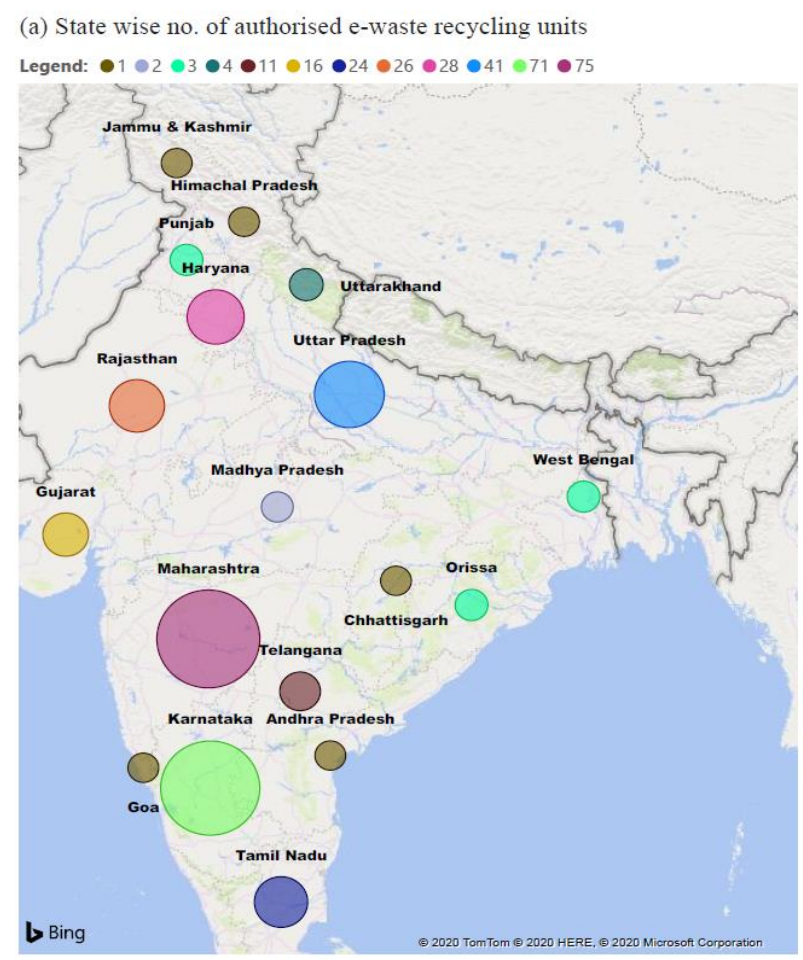

(b) State wise e-waste recycling plant capacity

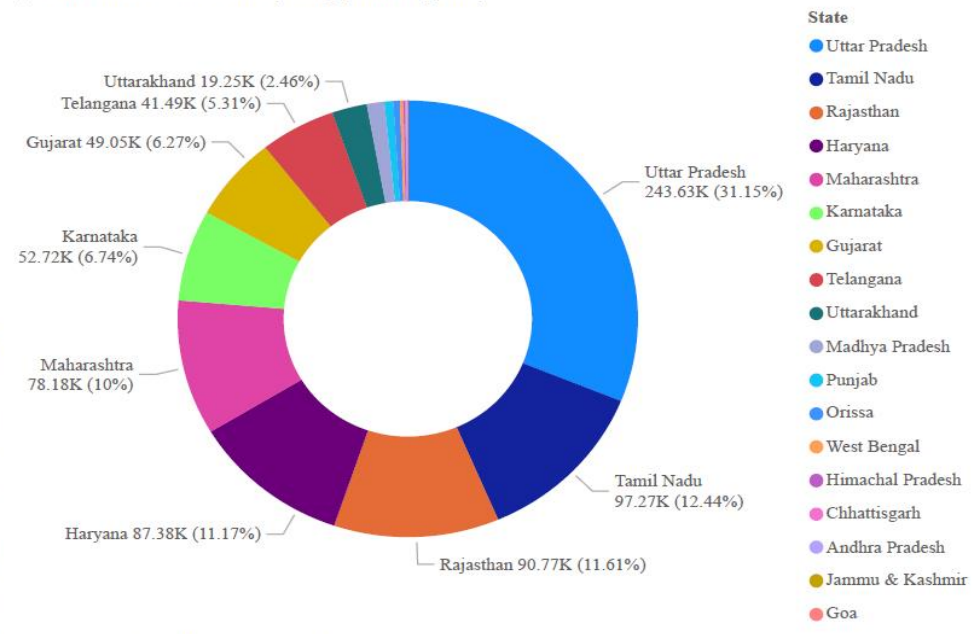

(c) e-waste handling capacity Vs e-waste generation

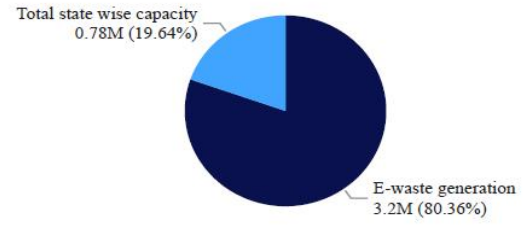

Fig. 2: State-wise location of recycling units with installed capacity (as of 27/06/2019)

\section{Materials and Methods}

This section highlights the overview of e-waste collection policy CSFs, research gaps, and the importance of fuzzyDEMATEL method in relation to the proposed methodology.

\subsection{Implications of the e-waste collection policy}

A significant driver of e-waste collection policy is the prevailing culture that relates to the consumption pattern, public awareness and disposal behaviour. Li et al. (2016) studied the impact of e-waste culture on improving collection activities and its overall sustainable management. Various countries have started to pay attention to the ewaste policy and identify those local variables or drivers that assist in the development of sustainable formal recycling and safe disposal system (Triguero et al. 2016). A study by Carisma (2009) measured the socio-culture and economics aspects as prominent drivers of e-waste management policy in the Philippines. Similarly, in Taiwan (Shih 2017), there is a Recycling Fund Management Board (RFMB), which analyzed the e-waste policy, intending to maximize the recycling rate as well as to improve the fund allocation system. They found flexibility, fairness and promotion are the key drivers of improvement in the e-waste recycling rate. Triguero et al. (2016) also reviewed the waste management policies of 28 European countries and identified three primary drivers that influence the waste 
management policy. These are Government responsibility to pay subsidy for waste management; Consumer responsibility to deposit the appropriate quantity of unsorted waste; Producer responsibility to pay the cost of waste management already included in the final prices of EEEs. Yu et al. (2014) argued that the policy instruments must take into account the development of the e-waste rules. They reviewed the e-waste policy of China and identified potential improvement areas like monitoring and auditing system, identification of location of the informal sector, sharing of information about treatment technologies with government and need of spreading awareness among public in the hinterland. Leclerc and Badami (2020) reviewed the EPR program of e-waste policy in Canada. They identified a few policy drivers that tend to add up in e-waste regulation such as enforcement mechanisms \& penalties, visibility of environmental handling fees and modulation of 3R (Reuse, Reduce and Recycling). Parajily et al. (2020) argue that the circular economy is an essential enabler for policy intervention in European countries. This driver may fill the gap between conventional drivers such as awareness campaigns, economic incentives, stricter regulations and consumer behaviour towards an e-waste policy. They suggested that the circular economy concept can influence the socio-economic culture and promote green practices. However, Borthakur and Govind (2017) argued that in developing countries like India, various factors like socio-cultural, economic, political, technological, infrastructural and environmental differences play a pivotal role in public acceptance of e-waste policy.

The designing of e-waste collection policy of India adopted a few points from the legislation of various developed nations. Some of the examples of different schemes adopted in India are deposit refund scheme, polluter pay, waste prevention, eco-efficiency etc. Some criticism is that the policies fell short of assessing efforts requires to implement such schemes. Other essential opportunities are to improve the policy taking a broader outlook like considerations in 'United Nations Agenda 2030' for Sustainable Development Goals (SDGs). For such perspective, the aim will be to identify the CSFs resulting from wider analysis of policy and establish casual relationships. The main priorities of the policy strategy are, therefore, to focus on the following area such as formulation of policies and to enact legislation to reduce waste generation, promote responsible public behaviour on waste management, promote waste segregation at source, the $3 \mathrm{Rs} \&$ recover energy from the waste, promotion of waste treatment and establishment of environmentally sound infrastructure for e-waste management (ITU 2018).

\subsection{Research gaps}

An extensive literature review shows that drafting effective e-waste collection policy has been a topic of significant concern for policymakers, as well as the consumers and various other stakeholders who are directly involved in ewaste management activities. The various previous studies have focused on the barriers or critical analysis of the 
implementation of e-waste management issues. Minimal research is found concentrated on the interrelation among the CSFs of e-waste collection policy in the context of developing countries like India. Further, no studies are found that identifies the influence and efficiency of e-waste collection policy or identify those factors that contribute to the foremost. Hence the current research undertakes to evaluate the CSFs for filling the gap and for promoting the importance of e-waste policy for the stakeholders. Moreover, it is hoped that this study can lead to a better understanding of e-waste collection and its policy development. The inclusion of outcomes of the study for e-waste policy development will lead maximize the e-waste collection in India.

\subsection{Research method}

The objective of the current study is to evaluate and identify the causal relationship between the CSFs. Various MCDM methods are available such as Analytic Hierarchy Process (AHP), Analytic Network Process (ANP), Interpretive Structural Modelling (ISM), and DEMATEL. Among these methods, AHP could not determine the relationship between factors (Parmar and Desai 2020). ANP only quantify and develop inner or direct dependency between factors (Tseng 2009). While ISM technique does establish the hierarchical interrelationships between the factors, however, it does not give a degree the influence between the factors. It does not divide the factors into cause and effect groups (Mangla et al. 2016). DEMATEL is one of MCDM methods and it not only develop the direct and indirect influence relationship within factors but also converts the influence factors relations into the cause group and effect group.

DEMATEL is a mathematical computational method, invented by Research Centre of Science and Human Affairs Program of the Battelle Memorial Institute Geneva (Gabus and Fontela 1973). DEMATEL can be an effective way to solve the various complex management problems by developing complex causal relationships with matrices or diagraphs. The matrices or diagraphs portray a contextual relationship among the factors or elements of the system. The results of DEMATEL represent the relationship between factors by categorizing them in cause and effect group (Tsai et al. 2020). Considering the biases and vagueness in human judgment in a real situation, a fuzzy set theory has been used to extend the traditional DEMATEL into fuzzy-DEMATEL (Karuppiah et al. 2020).

In waste management application, the fuzzy-DEMATEL method has been utilized by various researchers in analyzing the problem. Tseng and Lin (2009) identified critical issues and developed a cause and effect model for municipal solid waste management in Metro Manila. dos Muchangos et al. (2015) recognized the influential barriers to municipal solid waste management policy planning in Maputo city, Mozambique. Wang et al. (2017) analyzed the barriers of formal enterprises of household e-waste collection in China. Sahu et al. (2018) modelled the enablers of green e-waste management practices for mobile phone companies in India. Sharma et al. (2020) identified as 
circular economy concept the most influencing key enablers of e-waste management in India. Singhal et al. (2020) examined various critical factors for remanufacturing companies in India. Hence, fuzzy-DEMATEL is adopted here to develop contextual relations between various influencing CSFs for acceptability of e-waste policy in the Indian context.

The fuzzy-DEMATEL method consists of the following steps:

Step 1: To establish an expert committee

Literature review and brainstorming/critical discussion are necessary to ascertain the research problem. For critical discussion, an expert panel is formed as a three-member expert committee. The committee composes of following: one from the recycling industry, one from waste management consultancy and one expert from an academic background. All experts are capable of problem-solving and have significant knowledge of e-waste management comprising of policymaking, designing of e-waste handling and in e-waste management. The responses are collected through telephonic interview, email conversation and expert's webinars.

Step 2: To construct the initial fuzzy direct relationship matrix $(\widetilde{\mathrm{A}})$ for each expert $(k)$

In this step, for qualitative judgment, expert committee is asked to rate CSFs on a Triangular fuzzy number (TFN) scale as presented in Table 2. Here, $\tilde{a}_{i j k}=\left(l_{i j k}, m_{i j k}, u_{i j k}\right)$ indicates the degree of influence factor $i$ on factor $j$ while $k$ indicates number of experts, and $\mathrm{n}$ indicates number of factors. Then for each expert a $n \times n$ non-negative fuzzy direct relationship matrix is established as shown in equation (1).

$\widetilde{\mathrm{A}}=\left[\begin{array}{cccc}0 & \tilde{a}_{12} & \cdots & \tilde{a}_{1 n} \\ \tilde{a}_{21} & 0 & \cdots & \tilde{a}_{2 n} \\ \vdots & \vdots & \ddots & \vdots \\ \tilde{a}_{n 1} & \tilde{a}_{n 2} & \cdots & 0\end{array}\right]_{n \times n}$

Table 2: TFNs linguistic scale

\begin{tabular}{lcc}
\hline Definition of linguistic variables & $\begin{array}{c}\text { Intensity of } \\
\text { fuzzy scale }\end{array}$ & $\begin{array}{c}\text { TFN } \\
(l, m, u)\end{array}$ \\
\hline No influence (NI) & $\tilde{0}$ & $(0.00,0.00,0.25)$ \\
Very low influence (VL) & $\tilde{1}$ & $(0.00,0.25,0.50)$ \\
Low influence (L) & $\tilde{2}$ & $(0.25,0.50,0.75)$ \\
High influence (H) & $\tilde{3}$ & $(0.50,0.75,1.00)$ \\
Very high influence (VH) & $\tilde{4}$ & $(0.75,1.00,1.00)$ \\
\hline
\end{tabular}

253 Step 3: To develop defuzzified direct relationship matrix

254 Initial fuzzy direct relationship matrix of each expert is defuzzified into crisp form. The development of Defuzzified 

(2) to (8).

(1) Normalization:

259

$x l_{i j}^{k}=\frac{\left(l_{i j}^{k}-\min l_{i j}^{k}\right)}{\Delta_{\min }^{\max }}$

260

$x m_{i j}^{k}=\frac{\left(m_{i j}^{k}-\min l_{i j}^{k}\right)}{\Delta_{\min }^{\max }}$

$261 x u_{i j}^{k}=\frac{\left(u_{i j}^{k}-\min l_{i j}^{k}\right)}{\Delta_{\min }^{\max }}$

262 Where $\Delta_{\min }^{\max }=\max u_{i j}^{k}-\min l_{i j}^{k}$

263 (2) Compute left (ls) and right (us) spread of normalized fuzzy numbers:

$264 x \quad x \mathrm{ls}_{i j}^{k}=\frac{x m_{i j}^{k}}{\left(1+x m_{i j}^{k}-x l_{i j}^{k}\right)}$

$265 x \mathrm{us}_{i j}^{k}=\frac{x u_{i j}^{k}}{\left(1+x u_{i j}^{k}-x m_{i j}^{k}\right)}$

266 (3) Compute total normalized crisp value:

$267 \quad x_{i j}^{k}=\frac{\left[x \mathrm{~s}_{i j}^{k}\left(1-x \mathrm{~s}_{i j}^{k}\right)+x u_{i j}^{k} * x u_{i j}^{k}\right]}{\left[1-x \mathrm{~s}_{i j}^{k}+x \mathrm{us}_{i j}^{k}\right]}$

268 (4) Compute crisp value:

$269 z_{i j}^{k}=\min l_{i j}^{k}+x_{i j}^{k} * \Delta_{\min }^{\max }$

270 Step 4: Development of an average direct relationship matrix $\left(A_{i j}\right)$, normalized direct relationship matrix $(D)$ and

271 Total Relation Matrix (TRM) 'T'

272 The aggregate DDRM is obtained from each expert by developed average direct relationship matrix (ADRM) using 273 equation (9).

274

$A_{i j}=\frac{1}{k}\left(z_{i j}^{1}+z_{i j}^{2}+\cdots+z_{i j}^{k}\right)$

275 The normalization of ADRM is done using equation (10)

276

$D=\frac{A}{S} \quad$ Where $S=\max \left(\max _{1 \leq i \leq n} \sum_{j=1}^{n} a_{i j}, \max _{1 \leq i \leq n} \sum_{i=1}^{n} a_{i j}\right)$

277 The total relationship matrix $T$ is computed by equation (11)

$278 T=D(I-D)^{-1}$ Where $I$ is an identity matrix

279 Step 5: To calculate row sum $\left(\mathrm{R}_{i}\right)$ and column sum $\left(\mathrm{C}_{j}\right)$ of TRM $(T)$. Equation 12 and 13 are used to find $\mathrm{R}_{i}$ and $\mathrm{C}_{j}$.

$\mathrm{R}_{i}=\left[\sum_{j=1}^{j=n} T_{i j}\right]_{n * 1}$ 
Step 6: To establish the cause and effect relationship

283 The value of $R_{i}$ and $C_{j}$ determine the cause or effect nature of a factor based on the computation of $\left(\mathrm{R}_{i}+\mathrm{C}_{j}\right)$ and $284\left(R_{i}-\mathrm{C}_{j}\right)$. Where, $\left(\mathrm{R}_{i}+\mathrm{C}_{j}\right)$ represent the degree of prominence of the factor " $i$ " in the entire system and $\left(R_{i}-\mathrm{C}_{j}\right)$ represent net cause and effects that factor " $i$ " contributes to the system. Furthermore, the interrelation among the CSFs is developed based on the threshold value $\alpha$, which is calculated by using equation (14).

$\alpha=\frac{\sum_{i=1}^{n^{\prime}} \sum_{j=1}^{n^{\prime}} T_{i j}}{n^{\prime}}$

288 The threshold value $\alpha$ is computed from the matrix $T$. When the values in the matrix $T$ exceed $\alpha$, it indicates a strong interrelation between factors. The weak relationship between the factors are generally eliminated.

\subsection{Proposed research framework}

291 The framework consists of two phases. The first phase identifies and lists CSFs related to e-waste collection policy based on an extensive literature survey available at various databases. These databases are google scholar, Web of 293 Science, Scopus, e-waste reports and various magazines. Taking opinion from expert committee, a total of twentythree CSFs is shortlisted. The listed CSFs is classified into six categories, (1) Research \& development, (2) 295 Education and social behaviour, (3) Economic instrument, (4) Traceability, (5) Responsibility, and (6) Legislation \& Regulation as listed in Table 3. The second phase involves application of fuzzy DEMATEL technique to develop 297 the interrelationship among the CSFs for analysis of causal relation between one CSF over other. Finally, the findings are discussed with experts to assist them in reframing e-waste policy and develop tactical schemes by policymakers for successful and wide acceptance level of e-waste policy. The various steps adopted in the proposed research framework for evaluation of the CSFs is illustrated in Fig. 3. 


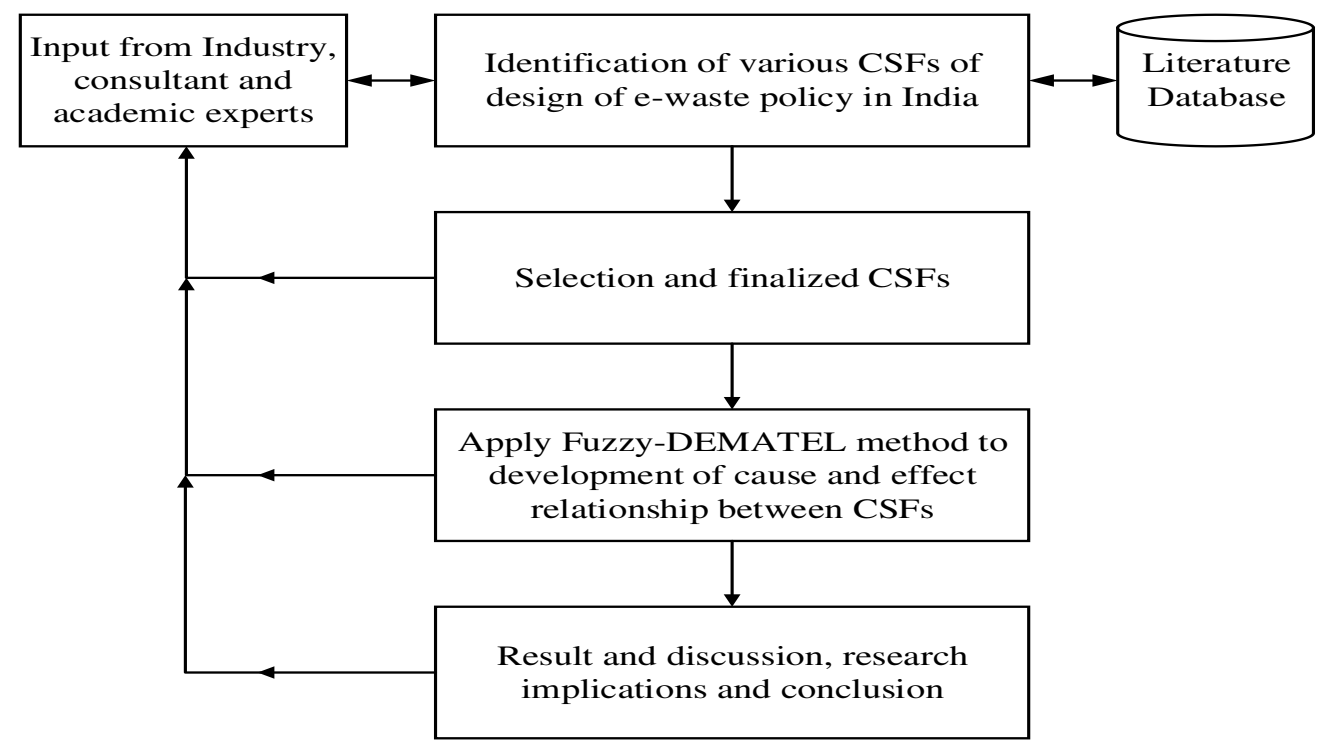

Fig.3: The various steps involved in the proposed research framework

Table 3: Identified CSFs of e-waste collection policy

\begin{tabular}{|c|c|c|c|}
\hline Implication factors & CSFs & \# & Explanation \\
\hline $\begin{array}{l}\text { Research \& } \\
\text { development }\end{array}$ & Green practices & K1 & $\begin{array}{l}\text { To develop a framework of green recycling activities for } \\
\text { handling e-waste. }\end{array}$ \\
\hline (II) & $\begin{array}{l}\text { Technology } \\
\text { involvement }\end{array}$ & $\mathrm{K} 2$ & $\begin{array}{l}\text { To identify environmentally sound technologies and } \\
\text { possess adequate technical capabilities, requisite } \\
\text { facilities and carbon footprint monitoring. }\end{array}$ \\
\hline & $\begin{array}{l}\text { Infrastructure } \\
\text { development }\end{array}$ & K3 & $\begin{array}{l}\text { To provide guidelines for Infrastructure to handle the } \\
\text { rapidly growing streams of e-waste. }\end{array}$ \\
\hline
\end{tabular}

Education and social behaviour

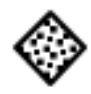

Economic

Instrument

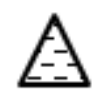

Environmental

program

Government

initiatives

Training \& empowerment

Publicity

Public ethics

Stakeholders awareness about circular economy Entrepreneur support

Funding schemes

Tax incentive
K4 To incorporate and progressively acquire knowledge on specific e-waste effect on environment to adopt an environmentally friendly approach.

K5 To develop e-waste awareness program under 'Swachh Bharat Mission' about safe disposal of e-waste.

K6 To develop a suitable platform for an employee training program like skill development for both formal and informal actors.

K7 To increase the environmental awareness among consumers and establish a channel for expressing willingness to participate in the e-waste recycling activities.

K8 Shaping ethical relations of consumers about responsibility to dispose e-waste by proper channel.

K9 To promote circular economy concepts for recovery, reuse and recycling of e-waste.

K10 To provide details of various start-up under subsidies schemes that encourage development of business model for e-waste handling or recycling.

K11 To explain flexible financial support guidelines for the stakeholders in terms of hazardous waste disposal, real data of e-waste collection and recycling.

K12 To explain tax provision for the consumer who brings their e-waste to be recycled and to agencies/firms that collect e-waste for recycling.
Authors

Wath et al. 2010;

Liang and Sharp

2016; Huisman et

al. 2019

Pérez-Belis et al. 2015; Guarnieri et al. 2016; Jafari et al. 2017; Wang et al. 2018; Ramzan et al. 2019

Redmond et al. 2008; Wath et al. 2010; Liang and Sharp 2016 
Responsibility

因

Traceability

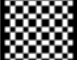

Legislation \&

Regulation
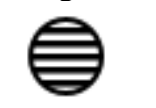

\section{Extended}

producer

responsibility

(EPR)

Corporate social responsibility

(CSR)

Individual

stakeholders

responsibility

Information

visibility \&

transparency

Transboundary

movement

Estimation of e-

waste

generation

Collection

mechanism

Monitoring \&

enforcement

Legal

framework

Regulatory

framework

Certification

and Licensing
K13 To encourage manufacturer/producer takes responsibility for managing the environmental impacts of their products through entire life cycle of a product.

K14 To provide guidelines to the business community to engage in CSR activity related to their e-waste.

K15 To clarify the responsibilities of all stakeholders under the regulation.

K16 Involve all stakeholders, including the upstream and downstream member of e-waste supply chain to keep necessary data and information about recycling activities.

K17 To comply with the international treaties for export or import and follow Basel Convention rules.

K18 To develop a framework for a national database of ewaste generation estimation on a yearly basis.

K19 To provide details of various e-waste collection methods in policy guidelines.

K20 To secure the outcomes of e-waste management at present as well as in the future.

K21 To establish a legal framework for e-waste management and include the provision of reusable materials and hazardous substances in mainstream business.

K22 To establishing a duty of local authorities to develop a waste management framework, i.e., promote an integrated municipal solid waste management for identified e-waste.

K23 To develop a flexible framework for providing licensing as collectors, recyclers, logistic provider and also develop certification procedures for the producers who generate e-waste.

\section{\# - Notations}

\section{Case analysis and application of fuzzy-DEMATEL for e-waste collection policy}

The authors developed a platform for examining CSFs related to the acceptance of India's e-waste policy.

Incorporated the perspective of the various stakeholders that are necessary for a successful implication of sustainable e-waste management system. The data required for the fuzzy-DEMATEL analysis is collected in the state of Rajasthan in India. There are recent studies which analyzed that method by taking the inputs from three to five experts (Parmar and Desai 2020; Singhal et al. 2020).

At first, based on the expert's opinion, the initial pairwise matrices are built. The inputs are filled by experts in a 0 to 4 scale (Table 2) depending upon the influence of one factor over another factor and then converted into a fuzzy linguistic scale as presented in Table 4 . The same is then defuzzified in crisp values by using equation (5-8). The DDRM obtained is tabulated in Table 5. Next, the ADRM is develop by aggregating the experts input into one matrix using equation (9) and then normalize the ADRM by using equation (10), the outcome is presented in Table 

the CSFs, where $\mathrm{R}$ and $\mathrm{C}$ are computed using equation (12).

318 Table 4: Initial fuzzy direct relation matrix for - expert 2

\begin{tabular}{|c|c|c|c|c|c|c|}
\hline$\overline{\mathrm{CSFs}}$ & K1 & K2 & $\ldots$ & $\ldots$ & K22 & K23 \\
\hline K1 & 0 & $(0.25,0.50,0.75)$ & $\ldots$ & $\ldots$ & $(0.50,0.75,1.00)$ & $(0.00,0.25,0.50)$ \\
\hline K2 & $(0.25,0.50,0.75)$ & 0 & $\ldots$ & $\ldots$ & $(0.50,0.75,1.00)$ & 0 \\
\hline K3 & $(0.25,0.50,0.75)$ & $(0.00,0.25,0.50)$ & $\ldots$ & $\ldots$ & $(0.25,0.50,0.75)$ & 0 \\
\hline K4 & $(0.25,0.50,0.75)$ & $(0.50,0.75,1.00)$ & $\ldots$ & $\ldots$ & $(0.25,0.50,0.75)$ & $(0.50,0.75,1.00)$ \\
\hline$\cdots$ & $\cdots$ & $\cdots$ & $\cdots$ & $\cdots$ & $\cdots$ & $\cdots$ \\
\hline$\ldots$ & $\ldots$ & $\ldots$ & $\ldots$ & $\ldots$ & $\ldots$ & $\ldots$ \\
\hline K19 & $(0.50,0.75,1.00)$ & $(0.25,0.50,0.75)$ & $\ldots$ & $\ldots$ & $(0.25,0.50,0.75)$ & $(0.75,1.00,1.00)$ \\
\hline K20 & 0 & $(0.75,1.00,1.00)$ & $\ldots$. & $\ldots$. & $(0.50,0.75,1.00)$ & $(0.50,0.75,1.00)$ \\
\hline K21 & $(0.25,0.50,0.75)$ & $(0.75,1.00,1.00)$ & $\ldots$ & $\ldots$ & $(0.25,0.50,0.75)$ & $(0.00,0.25,0.50)$ \\
\hline K22 & 0 & $(0.00,0.25,0.50)$ & $\ldots$ & $\ldots$ & 0 & $(0.00,0.25,0.50)$ \\
\hline K23 & 0 & $(0.25,0.50,0.75)$ & $\ldots$ & $\ldots$ & $(0.50,0.75,1.00)$ & 0 \\
\hline
\end{tabular}

Table 5: DDRM for - expert 2

\begin{tabular}{lllllll}
\hline CSFs & K1 & K2 & $\ldots$. & $\ldots$. & K22 & K23 \\
\hline K1 & 0.033 & 0.733 & $\ldots$. & $\ldots$. & 0.033 & 0.000 \\
K2 & 0.500 & 0.033 & $\ldots$. & $\ldots$. & 0.000 & 0.000 \\
K3 & 0.500 & 0.500 & $\ldots$. & $\ldots$. & 0.000 & 0.000 \\
K4 & 0.500 & 0.966 & $\ldots$. & $\ldots$. & 0.000 & 0.000 \\
$\ldots$. & $\ldots$. & $\ldots$. & $\ldots$. & $\ldots$. & $\ldots$. & $\ldots$. \\
$\ldots$. & $\ldots$. & $\ldots$. & $\ldots$. & $\ldots$. & $\ldots$. & $\ldots$. \\
K19 & 0.733 & 0.966 & $\ldots$ & $\ldots$. & 0.000 & 0.000 \\
K20 & 0.033 & 0.00 & $\ldots$. & $\ldots$. & 0.000 & 0.000 \\
K21 & 0.500 & 0.266 & $\ldots$. & $\ldots$. & 0.000 & 0.000 \\
K22 & 0.033 & 0.500 & $\ldots$. & $\ldots$. & 0.000 & 0.000 \\
K23 & 0.033 & 0.500 & $\ldots$. & $\ldots$. & 0.733 & 0.033 \\
\hline
\end{tabular}

Table 6: Normalised ADRM of all three experts

\begin{tabular}{lllllll}
\hline CSFs & K1 & K2 & $\ldots$. & $\ldots$. & K22 & K23 \\
\hline K1 & 0.011 & 0.244 & $\ldots$. & $\ldots$. & 0.011 & 0.000 \\
K2 & 0.167 & 0.011 & $\ldots$. & $\ldots$. & 0.000 & 0.000 \\
K3 & 0.167 & 0.167 & $\ldots$. & $\ldots$. & 0.000 & 0.000 \\
K4 & 0.167 & 0.322 & $\ldots$. & $\ldots$. & 0.000 & 0.000 \\
$\ldots$. & $\ldots$. & $\ldots$. & $\ldots$. & $\ldots$. & $\ldots$. & $\ldots$. \\
$\ldots$. & $\ldots$. & $\ldots$. & $\ldots$. & $\ldots$. & $\ldots$. & $\ldots$. \\
K19 & 0.322 & 0.244 & $\ldots$. & $\ldots$. & 0.000 & 0.000 \\
K20 & 0.000 & 0.167 & $\ldots$. & $\ldots$. & 0.000 & 0.000 \\
K21 & 0.322 & 0.089 & $\ldots$. & $\ldots$. & 0.000 & 0.000 \\
K22 & 0.000 & 0.089 & $\ldots$. & $\ldots$. & 0.000 & 0.000 \\
K23 & 0.089 & 0.000 & $\ldots$. & $\ldots$. & 0.000 & 0.000 \\
\hline
\end{tabular}

Table 7: Total relation matrix

\begin{tabular}{lllllll}
\hline CSFs & K1 & K2 & $\ldots$ & $\ldots$ & K22 & K23 \\
\hline
\end{tabular}




\begin{tabular}{|c|c|c|c|c|c|c|}
\hline K1 & 0.024 & 0.100 & $\ldots$ & $\ldots$ & 0.004 & 0.000 \\
\hline K2 & 0.075 & 0.031 & $\ldots$ & $\ldots$ & 0.000 & 0.000 \\
\hline K3 & 0.065 & 0.075 & $\ldots$ & $\ldots$ & 0.000 & 0.000 \\
\hline K4 & 0.082 & 0.130 & $\ldots$ & $\ldots$ & 0.000 & 0.000 \\
\hline$\cdots$ & $\ldots$ & $\ldots$ & $\ldots$ & $\ldots$ & $\ldots$ & $\ldots$ \\
\hline $\begin{array}{l}\ldots . \\
V 1\end{array}$ & $\ldots$ & & $\cdots$ & $\cdots$ & & \\
\hline K19 & 0.101 & 0.130 & $\ldots$ & $\ldots$ & 0.000 & 0.000 \\
\hline K20 & 0.024 & 0.019 & $\ldots$ & $\ldots$ & 0.000 & 0.000 \\
\hline K21 & 0.062 & 0.045 & $\ldots$ & $\ldots$ & 0.000 & 0.000 \\
\hline K22 & 0.022 & 0.074 & $\ldots$ & $\ldots$ & 0.000 & 0.000 \\
\hline K23 & 0.055 & 0.108 & $\ldots$ & $\ldots$ & 0.076 & 0.003 \\
\hline
\end{tabular}

Threshold value $\alpha=0.029$

Table 8: Final ranking of the CSFs

\begin{tabular}{lccccc}
\hline CSFs & $\begin{array}{c}\text { Degree of } \\
\text { influential impact } \\
(\mathrm{R})\end{array}$ & $\begin{array}{c}\text { Degree of } \\
\text { influenced impact }(\mathrm{C})\end{array}$ & $\begin{array}{c}\text { Prominence } \\
\text { factor } \\
(\mathrm{R}+\mathrm{C})\end{array}$ & $\begin{array}{c}\text { Prominence } \\
\text { Ranking }\end{array}$ & $\begin{array}{c}\text { Causal } \\
\text { relation } \\
(\mathrm{R}-\mathrm{C})\end{array}$ \\
\hline K1 & 0.632040 & 1.401847 & 2.033887 & 2 & -0.76981 \\
K2 & 0.629402 & 1.676864 & 2.306267 & 1 & -1.04746 \\
K3 & 0.501773 & 1.275289 & 1.777062 & 4 & -0.77352 \\
K4 & 0.718558 & 1.134744 & 1.853303 & 3 & -0.41619 \\
K5 & 0.850070 & 0.779014 & 1.629084 & 6 & 0.07105 \\
K6 & 0.660759 & 0.766005 & 1.426764 & 10 & -0.10525 \\
K7 & 0.722682 & 0.687598 & 1.410280 & 11 & 0.035084 \\
K8 & 0.833885 & 0.804836 & 1.638721 & 5 & 0.029049 \\
K9 & 0.912183 & 0.585466 & 1.497649 & 8 & 0.326718 \\
K10 & 0.484289 & 0.859820 & 1.344109 & 12 & -0.37553 \\
K11 & 0.320857 & 0.557696 & 0.878553 & 20 & -0.23684 \\
K12 & 0.842101 & 0.676106 & 1.518207 & 7 & 0.165995 \\
K13 & 0.690136 & 0.624467 & 1.314603 & 14 & 0.065669 \\
K14 & 0.329576 & 0.824864 & 1.154441 & 16 & -0.495290 \\
K15 & 0.764872 & 0.698479 & 1.463350 & 9 & 0.066393 \\
K16 & 0.558073 & 0.455615 & 1.013688 & 19 & 0.102458 \\
K17 & 0.733440 & 0.396058 & 1.129498 & 17 & 0.337382 \\
K18 & 0.943690 & 0.370911 & 1.314600 & 15 & 0.572779 \\
K19 & 0.737660 & 0.322488 & 1.060148 & 18 & 0.415172 \\
K20 & 0.434336 & 0.255213 & 0.689549 & 22 & 0.179123 \\
K21 & 0.455762 & 0.342629 & 0.798391 & 21 & 0.113133 \\
K22 & 0.495013 & 0.084116 & 0.579129 & 23 & 0.410897 \\
K23 & 1.332417 & 0.003448 & 1.335866 & 13 & 1.328969 \\
\hline
\end{tabular}

\section{Results and discussion}

328 To evaluate interconnect between the listed CSFs related to the e-waste collection policy, the $\mathrm{R}$ and $\mathrm{C}$ values are 329 computed from the total relation matrix (Table 8), and a causal diagraph is formed as presented in Fig. 4. The X330 axis denotes $(\mathrm{R}+\mathrm{C})$ which depicts prominence of factors (i.e. the cause group) and $\mathrm{Y}$-axis denotes $(\mathrm{R}-\mathrm{C})$ which is 331 the effect group. The effect group is also known as a receiver group. The positive value of CSFs on the Y-axis in the 332 figure represent cause group, while a negative value of CSFs on the Y-axis represent effect group. The advantage of 333 the causal diagraph is that it becomes easier to capture the complexity in decision making. The relative value of 

policymakers to consider CSFs for designing the e-waste collection policy.

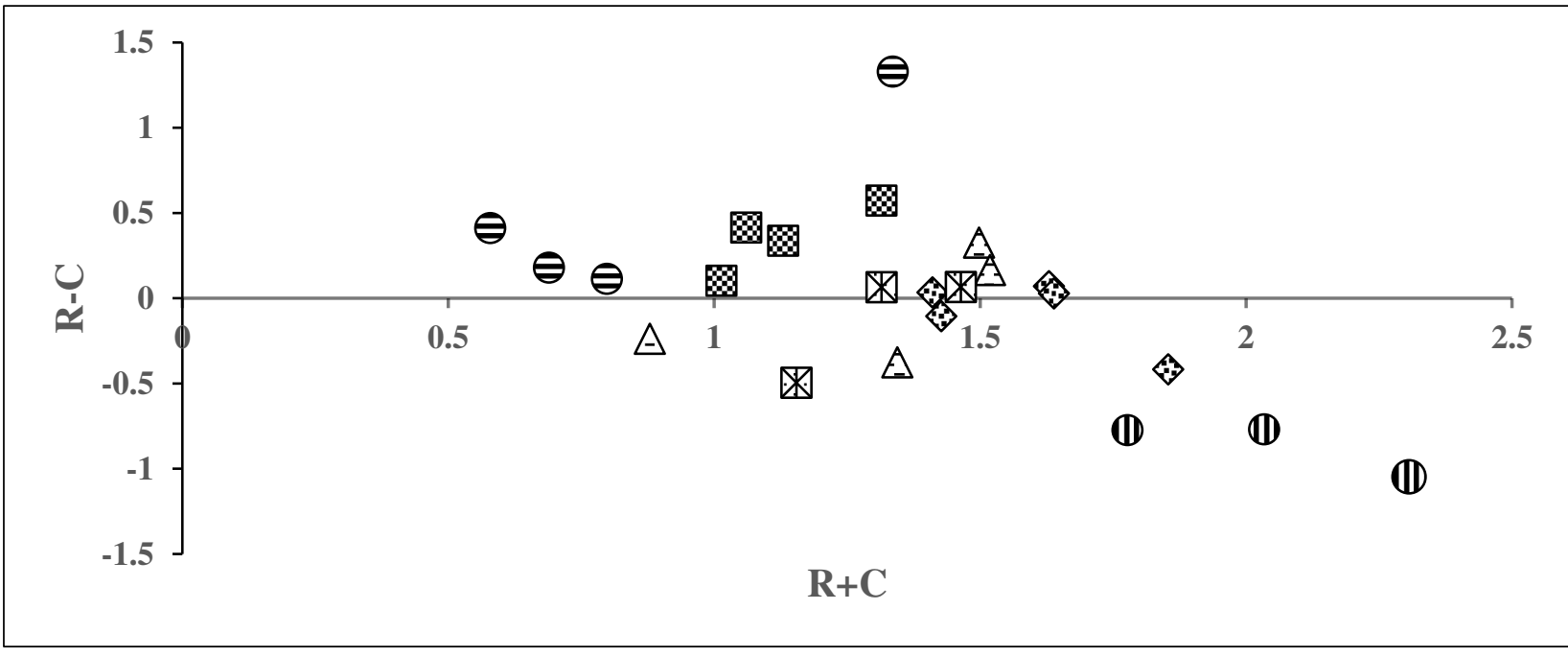

Fig. 4: Causal diagraph among CSFs

\subsection{Ranking of CSFs based on $\mathrm{R}+\mathrm{C}$ values}

339 The order of CSFs are evaluated through the degree of prominence $(R+C)$ values. The identified values of the 340 twenty-three factors based on the $\mathrm{R}+\mathrm{C}$ score are arranged in ascending order, as presented in Fig. 5. It is helpful to 341 identify the most critical and prominence factors. Among these various CSFs, Technology involvement (K2) is found to be most crucial factor followed by Green practices (K1), Environmental program (K4), Infrastructure development (K3), Public ethics (K8) and Government initiatives (K5). The prominence of CSFs have a great positive significant on e-waste collection policy and also get influenced by other CSFs. The policymakers need to be addressed and pay more attention to the performance of these CSFs for designing the e-waste collection policy. 


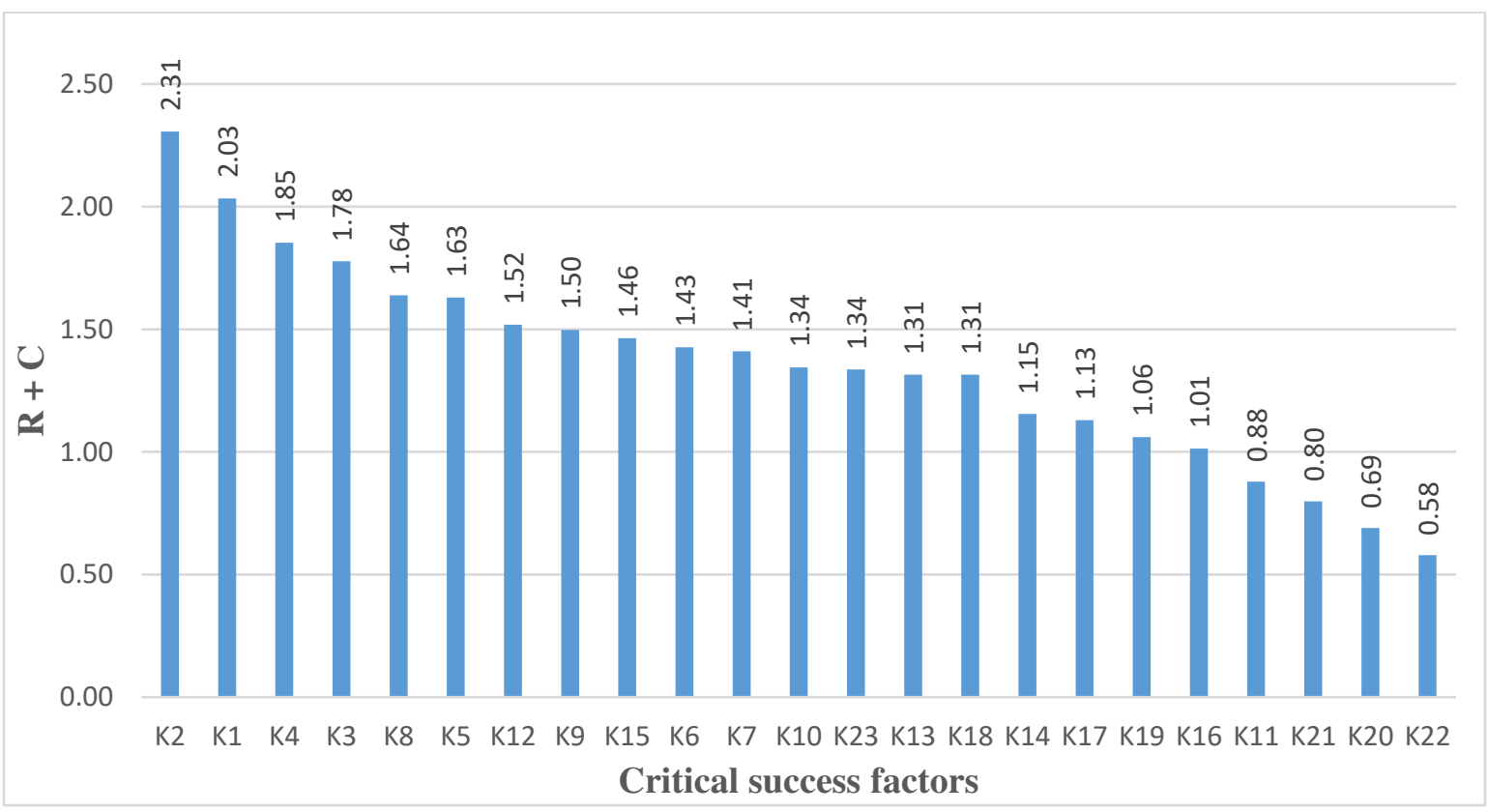

Fig.5: Prioritized the CSFs based on $\mathrm{R}+\mathrm{C}$ values

5.2. The categorization of CSFs into cause group and effect group based on R-C values

349 Based on their R-C score (Table 9), CSFs are classified into cause group and effect group. Out of twenty-three 350 CSFs, fifteen factors have a positive value of (R-C) and are put in the cause group. While the rest eight factors have negative (R-C) value and are identified as the effect group, refer Fig. 4.

352 The listed CSFs in the cause group are indicative of prominent independent factors that are greatly influencing other 353 factors. The highest positive value of R-C signifies that Certification and licensing (K23) followed by Public ethics 354 (K18), Collection mechanism (K19), Regulatory framework (K22) and Transboundary movement (K17) are the major driving CSFs. The R-C values of cause group CSFs are presented in Fig. 6. The primary indicators of the cause group are explained in Table 10. The key performance indicators for evaluating the implementation level of the prominent cause group CSFs need to be critical analysis by policymakers. 


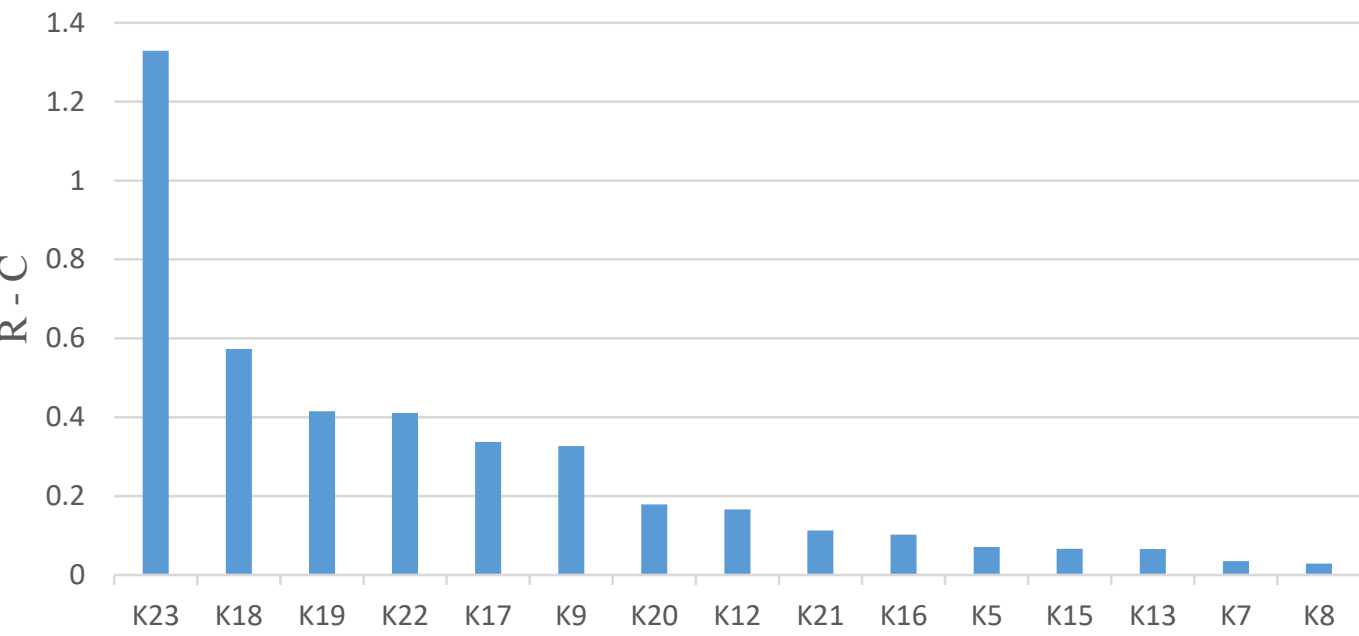

Critical success factors

Fig. 6: Cause group CSFs based on R-C score

Table 10: Cause group CSFs description

\begin{tabular}{|c|c|c|}
\hline S.no. & $\begin{array}{l}\text { Indicators check for cause } \\
\text { group }\end{array}$ & Description \\
\hline 1 & $\begin{array}{l}\text { The highest degree of } \\
\text { influential impact power of } \mathrm{R}\end{array}$ & $\begin{array}{l}\text { K23 - Certification and licensing has the highest degree of } \\
\text { influential impact power of } \mathrm{R} \text { equal to } 1.332 \text {, which means K23 } \\
\text { factor is the highest impact on the other CSFs. }\end{array}$ \\
\hline 2 & $\begin{array}{l}\text { Highest } \mathrm{R}-\mathrm{C} \text { score in the } \\
\text { group }\end{array}$ & $\begin{array}{l}\mathrm{K} 23 \text { - Certification and licensing has the highest value of } \mathrm{R}-\mathrm{C} \\
\text { equal to } 1.335 \text {, which indicates } \mathrm{K} 23 \text { least influenced by all other } \\
\text { factors. }\end{array}$ \\
\hline 3 & $\begin{array}{l}\text { Lowest } \mathrm{R}-\mathrm{C} \text { score in the } \\
\text { group }\end{array}$ & $\begin{array}{l}\text { K8 - Public ethics CSFs has the least value of R-C equal to } 0.83 \text {, } \\
\text { which indicates K8 highly influenced by all other factors. }\end{array}$ \\
\hline 4 & Highest $\mathrm{R}+\mathrm{C}$ score & $\begin{array}{l}\mathrm{K} 5 \text { - Government initiatives has the highest } \mathrm{R}+\mathrm{C} \text { score equals to } \\
1.64 \text {, and this CSFs has the potential to improve the system, and it } \\
\text { requires attention by the policymakers. }\end{array}$ \\
\hline
\end{tabular}

362 The effect group CSFs is listed in Fig. 7, which are the factors highly influenced by the other factors. The prominent 363 CSFs of the effect group are Technology involvement (K2), Infrastructure development (K3), Green practices (K1) 364 and CSR (K14). The significant effect CSFs group are explained in Table 11. The key indicator for the effect group CSFs needs to be identified to measure the performance of the CSFs. 


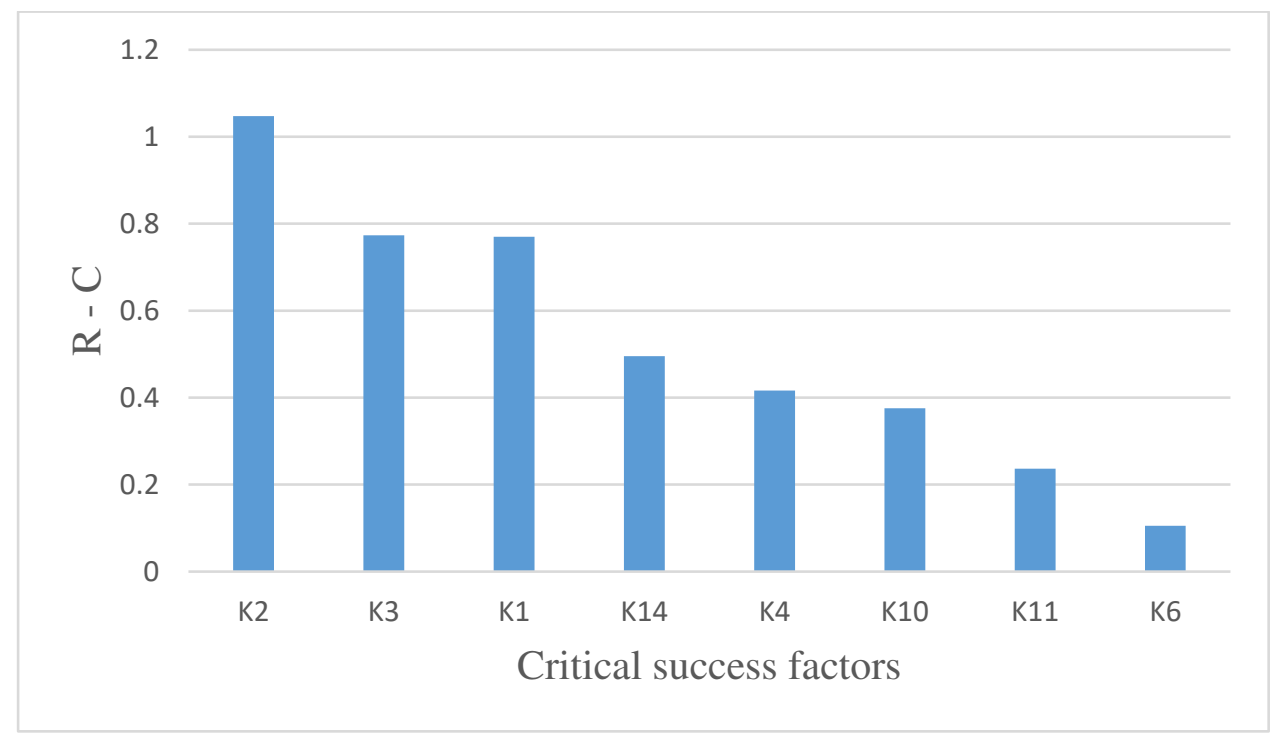

Fig. 7: Effect group CSFs based on $\mathrm{R}-\mathrm{C}$ value (values are negative)

Table 11: Effect group CSFs description

\begin{tabular}{|c|c|c|}
\hline S.no. & Indicators check for effect group & Description \\
\hline 1 & $\begin{array}{l}\text { The highest degree of influential } \\
\text { impact power of } R\end{array}$ & $\begin{array}{l}\text { K4 - Environmental program has the highest degree of } \\
\text { influential impact power of } R \text { equals to } 0.71 \text {, which means } \\
\text { K4 has the most operative factors of the group. }\end{array}$ \\
\hline 2 & Highest $\mathrm{R}-\mathrm{C}$ score in the group & $\begin{array}{l}\text { K6 - Training \& empowerment has the highest value of } \mathrm{R} \text { - } \\
\mathrm{C} \text { equals to }-0.105 \text {, which indicates all other factors } \\
\text { highly influence K6. }\end{array}$ \\
\hline 3 & Lowest $\mathrm{R}-\mathrm{C}$ score in the group & $\begin{array}{l}\mathrm{K} 2-\text { Technology involvement has the least value of } \mathrm{R}-\mathrm{C} \\
\text { equals to }-1.04 \text {, which indicates all other factors least } \\
\text { influence } \mathrm{K} 2 \text {. }\end{array}$ \\
\hline 4 & Highest $\mathrm{R}+\mathrm{C}$ score & $\begin{array}{l}\mathrm{K} 2-\text { Technology involvement has the highest } \mathrm{R}+\mathrm{C} \text { score } \\
\text { equals to } 2.30 \text {, and this CSFs is the most prominent factor } \\
\text { among other CSFs. }\end{array}$ \\
\hline
\end{tabular}

\subsection{Establishment of strategy interrelation map between causes and effects}

For the development of strategy interrelation map among the CSFs, the calculated threshold value $(\alpha)$ is 0.029 and it is computed by using equation (14). This value is used to eliminate the weak interrelations among the CSFs and highlight the only those CSFs whose value in TRM is greater than the threshold value. A total of 146 interrelations are developed between CSFs based on their values. Since the number of interrelations is large, it becomes complex to represent all the interrelations in one diagram. Therefore, strategy interrelations map is divided into interrelations between effects, interrelations between causes and interrelations between causes and effects and are shown in Fig. 8 . The number of interrelations among CSFs in cause group is more than the effect group. As shown in Fig. 8, 

and Estimation of e-waste generation (K18) show the maximum number of interrelations with other CSFs related of e-waste collection policy. In comparison, Corporate social responsibility (K14), Information visibility \& transparency (K16) and Monitoring \& enforcement (K20) emerge as the least influenced factors. The finding also indicates that Research \& development group implication CSFs are favorably influencing by other CSFs.

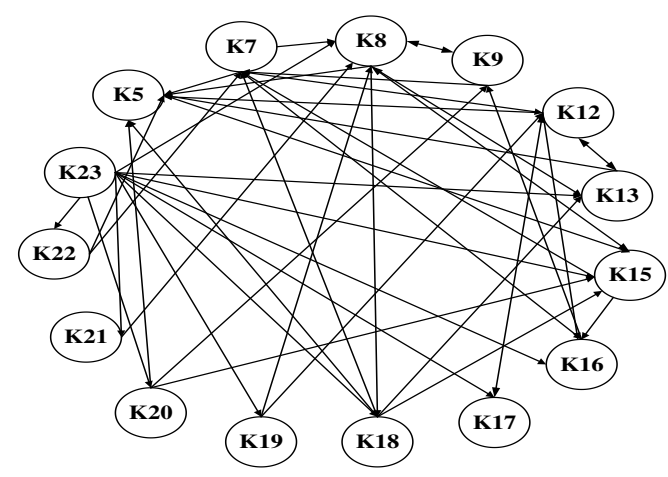

Inter-relationship between causes

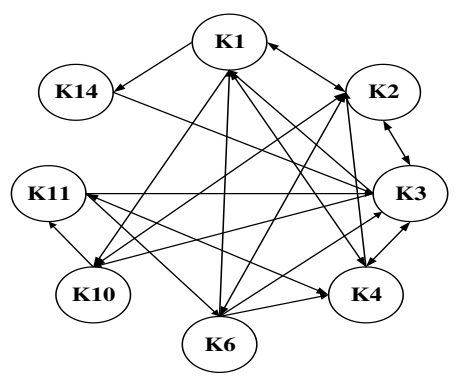

Inter-relationship between effects

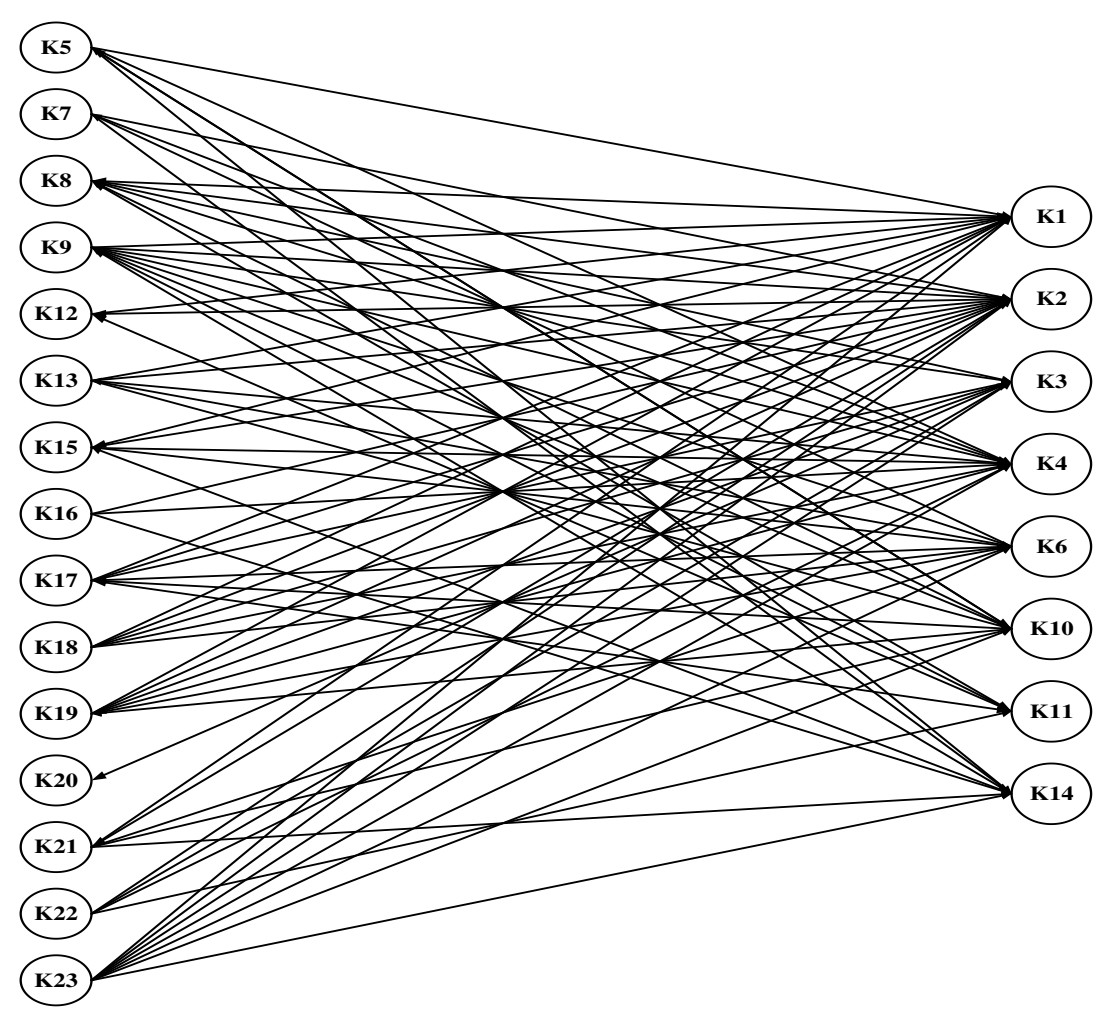

Inter-relationship between causes and effect

Fig. 8: Strategy interaction map

\section{Research implications}

The research puts forth significant clarification in e-waste collection related to policy matter and can assist in designing e-waste regulation. In the present study, the CSFs have been evaluated based on the input provided by an 
experts' committee. The study illustrates relations between the CSFs clarifying the prominence of CSFs in cause and effect sequence. A causal diagraph shows the connection among CSFs. The results are deemed useful for policymakers and practitioners to study the implication of policy design and implementation strategies for e-waste management. The prominent CSFs identified are discussed below:

- Technology involvement (K2) and green practices (K1) are the most prominent factors in the research \& development category. This finding is also supported in published literature (Wath et al. 2010; Kumar and Dixit 2018) as lack of research \& development in e-waste recycling are highlighted. There is a great need to provide impetus to research in various areas related to these problems. It is recommended that the policymaker works with stakeholders such as collectors and recyclers for understanding the technology involved in e-waste recycling activities under designing of e-waste collection policy.

- Environmental program (K4) is a useful option to spread e-waste awareness among consumers. The existing scenario is consumers are still not ready to change their consumption habits mainly because of lack of awareness (Parajuly et al. 2019). This issue led to e-waste storage in households and made traceability difficult for stakeholders to recover e-waste. The Government of India has started an awareness campaign named "Digital India Initiative" for covering all issues related to e-waste management. It is suggested that learning from the same may be addressed in the e-waste policy framework.

- Certification and licensing (K23) is found to have the highest degree of influential impact power (R) and it means there is need to develop a provision for stakeholders to obtain e-waste authentication and license approval bypassing red-tape hurdles quickly. Monitoring groups can implement a standard or random tracking method to detect violations of compliance. It can directly monitor suspected violators and share their findings with authorities or the public (Wang et al. 2020).

- Public ethics (K8) is one of the cause group factors with high relevance. Policymakers need to focus on it significantly. Policymakers can encourage the morality aspects of it and support responsible public behavior to increase participation in e-waste disposal activity.

- Stakeholder's awareness for the circular economy (K9) is one of the most crucial factors, and it provides a direct economic benefit. The circular economy needs to be promoted, as it is essential for sustainable ewaste management. It can ensure full utilization of e-waste under reuse, reduce, recycle and recover. The policy incentivizes this approach for stakeholders to understand and improve their business sustainability accordingly. 


\section{Conclusion}

420

E-waste management is a complex but crucial issue in developing countries, especially in India, where the unorganized sector conducts activities in an unethical manner that harms the ecosystem. The e-waste policy has nation-wide implications and stakeholders need to comply with and assist the implementation of the robust e-waste management system. In the context of 'United Nations Agenda 2030' for SDGs of e-waste management, the policymakers are under pressure to design a robust e-waste collection policy that is largely acceptable to various stakeholders. Here, we presented an in-depth analysis of the CSFs based on discussion with the experts committee. There is a lack of research to find out the relationship between the various CSFs of e-waste collection policy. To the best of our knowledge, this is a novel study, which not only determines the CSFs facilitating the design of e-waste collection policy but also examines the degree of criticality of the factors. The insights from the current study are believed to be beneficial for the stakeholders, the practitioners and the policymakers for enhancing acceptance of ewaste collection policy in the Indian context for successful implementation.

This research explored twenty-three CSFs with the help of a literature review and experts views. The FuzzyDEMATEL method has been applied to develop the interrelation among the CSFs and also examined the degree of prominence of the CSFs along with categorization into cause group and effect group. The research reveals that technology involvement (K2) and green practice (K1) factors have the highest importance among CSFs, which implies that sustainable e-waste management practices require more responsiveness. So, the policymakers may give more attention to the proponents of research \& development in e-waste handling. The stakeholders need to invest in improving their existing method. Moreover, awareness about the circular economy among stakeholders is found to be an essential factor for sustainable economic benefit. Further findings are that the legislation \& regulation CSFs fall under the cause group and are the most vital driver for designing of e-waste collection policy.

This study also pointed out the important limitations of the research, which can be viewed as a future scope. The present study is based on limited expert input which is subjective in nature, and alternative technique of ISMMICMAC can also be utilized to develop hierarchical relation between factors. Further, the authors also recommend empirical analysis, i.e. structural equation modelling that can be employed to conduct quantitative evaluation from a large sample to validate interrelation among CSFs. This study is conducted in the western part of India. The results of this study may differ from other study conducted at states of India and at a different country.

\section{Compliance with Ethical Standards}

Ethical Approval: All ethical requirements have been followed during this research work. 
449 Consent to Publish: All authors provide consent to publish this research article.

450 Authors Contributions: SS, Conceptualization, Methodology, Software, Data curation, Writing- Original draft 451 preparation, Investigation, Visualization, Software, Validation and Writing; MSD, Critical reviewing, Editing and 452 Supervision; SR, Conceptualization, Reviewing and Supervision.

453 Funding: This work is partially supported by Department of Science \& Technology, Rajasthan, India. Grant no: P $4547(3)$ Vpro/R\&D/2016/3262.

455 Availability of data and materials: Not applicable

456 Declaration of conflicting interests: The author(s) declared no potential conflicts of interest with respect to the 457 research, authorship, and/or publication of this article

\section{Reference}

Abbondanza MNM, Souza RG (2019) Estimating the generation of household e-waste in municipalities using primary data from surveys: A case study of Sao Jose dos Campos, Brazil. Waste Manag 85:374-384. https://doi.org/10.1016/j.wasman.2018.12.040

Al-Anzi BS, Al-Burait AA, Thomas A, Ong CS (2017) Assessment and modeling of E-waste generation based on growth rate from different telecom companies in the State of Kuwait. Environ Sci Pollut Res 24:2716027174. https://doi.org/10.1007/s11356-017-0190-0

Andarani P, Goto N (2014) Potential e-waste generated from households in Indonesia using material flow analysis. J Mater Cycles Waste Manag 16:306-320. https://doi.org/10.1007/ s10163-013-0191-0

Awasthi AK, Wang M, Wang Z, et al (2018) E-waste management in India: A mini-review. Waste Manag Res 36:408-414. https://doi.org/10.1177/0734242X18767038

Ayodeji, O O (2011) Assessment of the flow and driving forces of used electrical and electronic equipment into and within Nigeria. Master's Thesis. BTU Cottbus.

Baldé CP, Forti V, Gray V, et al (2017) The global e-waste monitor 2017

Borthakur A, Govind M (2017) How well are we managing E-waste in India: evidences from the city of Bangalore. Energy, Ecol Environ 2:225-235. https://doi.org/10.1007/s40974-017-0060-0

Cao J, Lu B, Chen Y, et al (2016) Extended producer responsibility system in China improves e-waste recycling: Government policies, enterprise, and public awareness. Renew Sustain Energy Rev 62:882-894. https://doi.org/10.1016/j.rser.2016.04.078

Carisma, B. (2009). Drivers of and barriers to E-waste management in the Philippines. Dissertation, Lund university Sweden 
Chaudhary K, Vrat P (2018) Case study analysis of e-waste management systems in Germany, Switzerland, Japan and India: A RADAR chart approach. Benchmarking 25:3519-3540. https://doi.org/10.1108/BIJ-07-20170168

Corsini F, Rizzi F, Frey M (2017) Extended producer responsibility: The impact of organizational dimensions on WEEE collection from households. Waste Manag 59:23-29. https://doi.org/10.1016/j.wasman.2016.10.046

CPCB (2019) E- Waste (Management) Amendment Rules, 2018. https://cpcb.nic.in/uploads/Projects/ EWaste/ewaste_amendment_notification_06.04.2018.pdf. Accessed 20 July 2020

Dias P, Machado A, Huda N, Bernardes AM (2018) Waste electric and electronic equipment (WEEE) management: A study on the Brazilian recycling routes. J Clean Prod 174:7-16. https://doi.org/10.1016/j.jclepro.2017.10.219

dos Muchangos LS, Tokai A, Hanashima A (2015) Analyzing the structure of barriers to municipal solid waste management policy planning in Maputo city, Mozambique. Environ Dev 16:76-89. https://doi.org/10.1016/j.envdev.2015.07.002

Forti V, Baldé CP, Kuehr R, Bel G (2020) The Global E-waste Monitor 2020

Gabus A, Fontela E (1973) Perceptions of the world problematique: Communication procedure, communicating with those bearing collective responsibility. Battelle Geneva Research Centre, Geneva, Switzerland.

Garlapati VK (2016) E-waste in India and developed countries: Management, recycling, business and biotechnological initiatives. Renew Sustain Energy Rev https://doi.org/10.1016/j.rser.2015.10.106

GSMA (2019) The Mobile Economy. Adweek 1-56

Guarnieri P, e Silva LC, Levino NA (2016) Analysis of electronic waste reverse logistics decisions using Strategic Options Development Analysis methodology: A Brazilian case. J Clean Prod 133:1105-1117. https://doi.org/10.1016/j.jclepro.2016.06.025

Huisman J, Stevels A, Baldé K, et al (2019) The e-waste development cycle - part I, introduction and country status. Elsevier Ltd

Islam MT, Huda N (2018) Reverse logistics and closed-loop supply chain of Waste Electrical and Electronic Equipment (WEEE)/E-waste: A comprehensive literature review. Resour Conserv Recycl 137:48-75. 
https://doi.org/10.1016/j.resconrec.2018.05.026

507

ITU (2018) Developing an e-waste national policy and regulatory framework for Malawi. https://www.itu.int/en/ITU-D/Climate-Change/Documents/2018/Developing_e-waste_ national_policy_and_regulatory_framework_Malawi.pdf Accessed 15 August 2020

Jafari A, Heydari J, Keramati A (2017) Factors affecting incentive dependency of residents to participate in e-waste recycling: a case study on adoption of e-waste reverse supply chain in Iran. Environ Dev Sustain 19:325-338. https://doi.org/10.1007/s10668-015-9737-8

Jecton AT, Timothy MW (2013) Towards an e-waste management framework in Kenya. info 15:99-113. https://doi.org/10.1108/info-05-2013-0028

Karuppiah K, Sankaranarayanan B, Ali SM (2020) An integrated approach to modeling the barriers in implementing green manufacturing practices in SMEs. J Clean Prod 121737. https://doi.org/10.1016/j.jclepro.2020.121737

Kim M, Jang YC, Lee S (2013) Application of Delphi-AHP methods to select the priorities of WEEE for recycling in a waste management decision-making tool. $\mathrm{J}$ Environ Manage 128:941-948. https://doi.org/10.1016/j.jenvman.2013.06.049

Kojima M, Yoshida A, Sasaki S (2009) Difficulties in applying extended producer responsibility policies in developing countries: Case studies in e-waste recycling in China and Thailand. J Mater Cycles Waste Manag 11:263-269. https://doi.org/10.1007/s10163-009-0240-x

Król A, Nowakowski P, Mrówczyńska B (2016) How to improve WEEE management? Novel approach in mobile collection with application of artificial intelligence. Waste Manag 50:222-233. https://doi.org/10.1016/j.wasman.2016.02.033

Kumar A, Dixit G (2018) An analysis of barriers affecting the implementation of e-waste management practices in India: A novel ISM-DEMATEL approach. Sustain Prod Consum 14:36-52. https://doi.org/10.1016/j.spc.2018.01.002

Leclerc SH, Badami MG (2020) Extended producer responsibility for E-waste management: Policy drivers and challenges. J Clean Prod 251:119657 https://doi.org/10.1016/ j.jclepro.2019.119657

Li J, Dong Q, Liu L, Song Q (2016) Measuring treatment costs of typical waste electrical and electronic equipment: A pre-research for Chinese policy making. Waste Manag 57:36-45. https://doi.org/10.1016/j.wasman.2016.02.025 
Liang L, Sharp A (2016) Development of an analytical method for quantitative comparison of the e-waste management systems in Thailand, Laos, and China. Waste Manag Res 34:1184-1191. https://doi.org/10.1177/0734242X16662333

Mmereki D, Li B, Li'ao W (2015) Waste electrical and electronic equipment management in Botswana: Prospects and challenges. J Air Waste Manag Assoc 65:11-26. https://doi.org/10.1080/10962247.2014.892544

Mangla SK, Govindan K, Luthra S (2016) Critical success factors for reverse logistics in Indian industries: a structural model. J of Clean Prod 129:608-621. https://doi.org/10.1016/ j.jclepro.2016.03.124

Morris A, Metternicht G (2016) Assessing effectiveness of WEEE management policy in Australia. J Environ Manage 181:218-230. https://doi.org/10.1016/j.jenvman.2016.06.013

Opricovic S, Tzeng GH (2003) Defuzzification within a multicriteria decision model. International Journal of Uncertainty, Fuzziness and Knowledge-Based Systems, 11:635-652

Okorhi JO, Amadi-Echendu JE, Aderemi HO, et al (2017) Disconnect between policy and practice in developing countries: Evidence of managing e-waste from Nigeria. African J Sci Technol Innov Dev 0:1-9. https://doi.org/10.1080/20421338.2017.1385134

Öztürk T (2015) Generation and management of electrical-electronic waste (e-waste) in Turkey. J Mater Cycles Waste Manag 17:411-421. https://doi.org/10.1007/s10163-014-0258-6

Parmar PS, Desai TN (2020) Evaluating Sustainable Lean Six Sigma enablers using fuzzy DEMATEL: A case of an Indian manufacturing organization. J Clean Prod 265:121802. https://doi.org/10.1016/j.jclepro.2020.121802

Parajuly K, Kuehr R, Awasthi AK, Fitzpatrick C, Lepawsky J, Smith E, Widmer R, Zeng X (2019) Future E-Waste Scenarios. Step (Bonn), UNU ViE SCYCLE (Bonn) \& UNEP IETC (Osaka).

Pérez-Belis V, Bovea MD, Simó A (2015) Consumer behaviour and environmental education in the field of waste electrical and electronic toys: A Spanish case study. Waste Manag 36:277-288. https://doi.org/10.1016/j.wasman.2014.10.022

Patil RA, Ramakrishna SA (2020) comprehensive analysis of e-waste legislation worldwide. Environ Sci Pollut Res 27:14412-14431. https://doi.org/10.1007/s11356-020-07992-1

Polat LÖ, Güngör A (2019) Network Design Problems in E-waste Management. Electron Waste Manag Treat Technol 77-102. https://doi.org/10.1016/b978-0-12-816190-6.00004-2 
Ramzan S, Liu CG, Munir H, Xu Y (2019) Assessing young consumers' awareness and participation in sustainable e-waste management practices: a survey study in Northwest China. Environ Sci Pollut Res 26:20003-20013. https://doi.org/10.1007/s11356-019-05310-y

Redmond J, Walker E, Wang C (2008) Issues for small businesses with waste management. Journal of environmental management. 88:275-285.

Rodrigues AC, Boscov MEG, Günther WMR (2020) Domestic flow of e-waste in São Paulo, Brazil: Characterization to support public policies. Waste Manag 102:474-485. https://doi.org/10.1016/j.wasman.2019.10.052

Sahu AK, Narang HK, Rajput MS (2018) A Grey-DEMATEL approach for implicating e-waste management practice. Grey Syst Theory Appl 8:84-99. https://doi.org/10.1108/GS-11-2017-0037

Salhofer S (2010) E-Waste Collection and Treatment Options: A Comparison of Approaches in Europe, China and Vietnam. In: Hdb Env Chem. pp 41-53

Sharma M, Joshi S, Kumar A (2020) Assessing enablers of e-waste management in circular economy using DEMATEL method: An Indian perspective. Environ Sci Pollut Res. https://doi.org/10.1007/s11356-02007765-w

Shih HS (2017) Policy analysis on recycling fund management for E-waste in Taiwan under uncertainty. J Clean Prod 143:345-355. https://doi.org/10.1016/j.jclepro.2016.12.103

Singhal D, Tripathy S, Jena SK (2020) Remanufacturing for the circular economy: Study and evaluation of critical factors. Resour Conserv Recycl 156:104681. https://doi.org/10.1016/j.resconrec.2020.104681

Singh A, Panchal R, Naik M (2020) Circular economy potential of e-waste collectors, dismantlers, and recyclers of Maharashtra: a case study. Environ Sci Pollut Res 27:22081-22099. https://doi.org/10.1007/s11356-02008320-3

Tsai FM, Bui TD, Tseng ML, Wu KJ, Chiu AS (2020) A performance assessment approach for integrated solid waste management using a sustainable balanced scorecard approach. J Clean Prod 251:119740.

Tseng ML, Lin YH (2009) Application of fuzzy DEMATEL to develop a cause and effect model of municipal solid waste management in Metro Manila. Environmental monitoring and assessment, 158:519. 
Tseng, M.L (2009) Application of ANP and DEMATEL to evaluate the decision-making of municipal solid waste management in Metro Manila. Environmental monitoring and assessment, 156:181.

Thavalingam V, Karunasena G (2016) Mobile phone waste management in developing countries: A case of Sri Lanka. Resour Conserv Recycl 109:34-43. https://doi.org/10.1016/j.resconrec.2016.01.017

Triguero A, Álvarez-Aledo C, Cuerva MC (2016) Factors influencing willingness to accept different waste management policies: empirical evidence from the European Union. J Clean Prod 138:38-46. https://doi.org/10.1016/j.jclepro.2016.05.119

Wang W, Qu Y, Liu Y, Zhang Y (2020) Understanding the barriers for Internet-based e-waste collection system in China. J Environ Plan Manag 63:629-650. https://doi.org/10.1080/09640568.2019.1601618

Wang W, Tian Y, Zhu Q, Zhong Y (2017) Barriers for household e-waste collection in China : Perspectives from formal collecting enterprises in Liaoning Province. J Clean Prod 153:299-308. https://doi.org/10.1016/j.jclepro.2017.03.202

Wang Z, Guo D, Wang X, et al (2018) How does information publicity influence residents' behaviour intentions around e-waste recycling? Resour Conserv Recycl 133:1-9. https://doi.org/10.1016/j.resconrec.2018.01.014

Wath SB, Dutt PS, Chakrabarti T (2011) E-waste scenario in India, its management and implications. Environ Monit Assess 172:249-262. https://doi.org/10.1007/s10661-010-1331-9

Wath SB, Vaidya AN, Dutt PS, Chakrabarti T (2010) A roadmap for development of sustainable E-waste management system in India. Sci Total Environ 409:19-32. https://doi.org/10.1016/j.scitotenv.2010.09.030

Yu L, He W, Li G, et al (2014) The development of WEEE management and effects of the fund policy for subsidizing WEEE treating in China. Waste Manag 34:1705-1714. https://doi.org/10.1016/j.wasman.2014.05.012 